\title{
Skeleton key
}

R. McNeill Alexander is renowned for his biomechanics textbooks, but in Human Bones (Pi Press, \$37.50) he provides a tour of the 213 bones of the human skeleton for a general audience. He explains how our skeletons form and function, and how knowledge of individual differences assists forensics and archaeology. Accompanying the text are stunning photographs, like this one of a Chinese woman's bound foot, taken by Aaron Diskin.

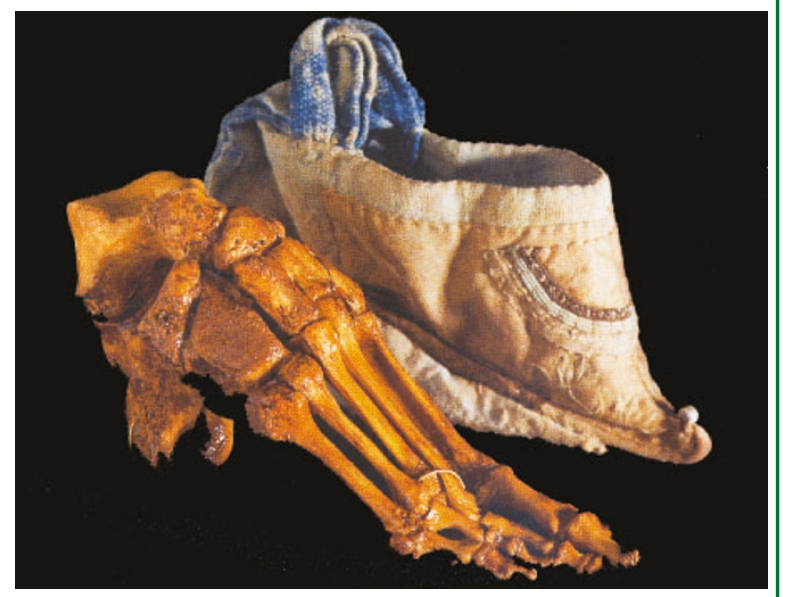

ice due to decline in coming years. Perhaps we should find out as much as possible about this environment while we can. Two new books offer some excellent views and useful information for those interested, from tourists to the completely focused specialist.

Norbert Wu's Under Antarctic Ice is crammed with images that I wish I had taken, many of which will inspire feelings of awe and disbelief in those unfamiliar with Antarctic marine biology. The pictures of anchor ice growing from the seabed are particularly different from previous books of Antarctic photos. There is also a fair bit of information at the front of the book that will be helpful to students from school to undergraduate level. My main concern is that the book falls a little between being a textbook and a coffee-table book. However, many people will take sheer pleasure from the pictures and not quibble about the balance between subjects.

David Thomas's infatuation with sea ice and the life associated with it drives him to work long and unusual hours. His book Frozen Oceans deals with pack ice: how it forms, the organisms living inside and under it, and how to study it. As with Wu's book, it suffers a little from being somewhere between a textbook and a book for lay readers with an interest in how cold oceans work. I would have liked to see more references to key and current literature, to make it more valuable to students, but the glossary and list of websites will be valuable. This will prove useful background reading for graduate students and scientists moving into polar marine science. It could also be valuable to tourists visiting the polar oceans. The descriptions of the biological communities living under the pack ice are very good, and I learnt something new about the volatile gases, including bromoform and methyl bromide, that are released from algae at the lower surfaces of sea ice. The book is clear and well written, and I particularly liked the descriptions of porridge, pancake and grease ice. Lloyd Peck is at the British Antarctic Survey, High Cross, Madingley Road, Cambridge CB3 OET, UK.

\section{Swine fever}

\section{The Whole Hog: Exploring the} Extraordinary Potential of Pigs by Lyall Watson

Profile: 2004.278 pp. $£ 16.99$, $\$ 24.95$

\section{Temple Grandin}

Wild pigs have adapted to live in many parts of the world, from the Arizona desert to the Asian rainforest. The hairless, wrinkly babirusa, which has strange tusks that grow out of the top of its snout, is the one pig species that cannot breed with others, owing to a chromosomal abnormality. The highly social white-lipped peccaries, from South America, spend hours grooming and smearing the stinking product of their scent glands on each other. Lyall Watson's narrative provides a detailed natural history of both the behaviour and the biology of these and other pigs.

The author is intimately involved with the animals he describes. He grew up in Africa and spent his childhood in the bush. He had a Zulu companion who taught him

\section{More books for Christmas}

In Vanity, Vitality, and Virility: The Science Behind the Products You Love to Buy (Oxford University Press, £18.99), John Emsley explains the chemistry behind the ingredients of everyday products such as sunscreens, anti-ageing creams, Viagra and disposable nappies.

Len Fisher's Weighing the Soul: The Evolution of Scientific Beliefs (Weidenfeld \& Nicolson, $£ 12.99)$ takes a look at why common sense has often proved to be the enemy of good science, at the struggles of scientists to overcome scepticism, and at how to distinguish the brilliant from the bizarre.

The Best American Science and Nature Writing 2004 (Houghton Mifflin, \$14) is edited this year which snakes are dangerous and which are safe. Watson explains how pigs are more gregarious than the ungulates that graze the plains. The social life of pigs is more like that of primates than cattle or sheep.

Pigs will eat just about anything. Watson maintains that this lack of specialization makes the pig more curious about its environment and less afraid of new things than animals with more specialized diets. In the porcine brain there are greater associative areas in the cortex, which may make pigs more willing to approach new things. In my own work, it was interesting to compare the behaviour of domestic pigs with that of hand-raised antelope. If a paper bag is thrown in the pen, the pigs will instantly approach and explore, whereas the antelope instantly flee. Antelope run away first, and look and explore later.

Watson's aim for The Whole Hog is to bring together all the information about wild and domestic pigs. He did a splendid job with the wild pigs, but the section on modern domestic pigs is weak. There are two odd omissions. The section on the pork industry does not discuss the animal-welfare controversies surrounding industrial-scale pig farms. And there is excellent information on the need to preserve the different species of wild pig, but no discussion of the dangers of a few large breeding companies narrowing the genetic diversity of domestic pigs.

At the end of the book, Watson challenges the reader with the question of whether animals can think and have consciousness. My own view, as a person with autism, is that language is not required for thinking, because I think in pictures instead of words. Maybe animals think in associations of sensorybased memories?

Temple Grandin is in the Department of Animal Sciences, Colorado State University, Fort Collins, Colorado 80523, USA. She is the author of Thinking in Pictures: Autism and Visual Thought (Vintage). by Steven Pinker and contains a thoughtprovoking selection of essays reprinted from US newspapers and magazines, with contributions from Daniel Dennett, Nicholas Wade and Max Tegmark among others.

Michael Hanlon's The Real Mars (Constable, $£ 25)$ is a sumptuously illustrated history of our attempts to explore the red planet, culminating with this year's successes in the form of Mars Express and the Spirit and Opportunity rovers.

In Ig Nobel Prizes 2: Why Chickens Prefer Beautiful Humans (Orion, £10.99), Marc Abrahams describes more of the bizarre and obscure areas of scientific research that have been honoured with an Ig Nobel prize. 